\title{
Application of Grouting Reinforcement of Deep Foundation Pit Damaged by Heavy Rain
}

\author{
Guangbiao Shao \\ School of civil engineering, Shandong Jianzhu University, Jinan, China \\ sgbou@126.com
}

\section{Keywords: Foundation pit; Soaked; Grouting; Reinforcement; Anchor}

\begin{abstract}
Grouting reinforcement technique is analyzed and designed in foundation pits which were damaged by rainstorm. Heavy rains led to a deep foundation pit are soaked and some slopes were collapse and the foundations of surrounding buildings were sunken. The causes of the accident are analyzed after emergency rescue. The main reason is foundation pit lateral groundwater with high water pressure, carrying a large number of soil particles of slope to foundation pit, and led to a collapse of the upper soil. Then the foundation pit reinforcement schemes are designed, which are active area of soil grouting reinforcement and self-drilling bolt added. Grouting can be filled dense with soil that damaged by rain, improve soil shear strength, increase the bearing capacity of anchor, thereby increasing the safety factor of foundation pit. Since the sealing curtain damaged, grouting in the pit top of slope will help repair sealing curtain and to prevent buildings around foundation pit generating uneven settlement. Using the grouting technology, the foundation pit is successfully completed and can provide technical references for similar projects.
\end{abstract}

\section{Introduction}

In recent years, a large number of deep foundation pit had been construction in the city, due to poor urban drainage system caused the roads water- logging, if deep foundation pit position low-lying, weak blocking drainage measures may lead to adverse water flow backward, which bring about foundation pit soaked by water immersion, to the foundation pit slope itself and the surrounding environment bring great safety hidden trouble, and even landslides and building damage accident [1 4]. In order to ensure the construction project smooth implementation, the need to reinforce the soaking pit, this paper, a deep foundation pit accident of foundation pit collapse was analyzed through tests, put forward the reinforcement design scheme, grouting at the top of slope played a major role, the example provide the necessary technical reference for similar projects.

\section{Engineering Situation}

A foundation pit excavation depth about $11 \mathrm{~m}$, north and south about $135 \mathrm{~m}$ long and $75 \mathrm{~m}$ wide from east to west. The design of foundation pit were two support section. Vertical excavation were performed at south and west side in which composite soil nailing wall support were constructed with soil nailing and double steel pipe pile and anchor and the high pressure jet grouting pile water curtain. Slope excavation were performed at north and east side in which prestressed anchor composite soil nailing wall were constructed. Large diameter tube well were used to dewatering at pit and the north and east slope top. Foundation pit supporting layout as shown in Fig. 1.

As shown in Fig. 2 for the west and south side of foundation pit supporting section, steel pipe pile diameter of $220 \mathrm{~mm}, 1.0 \mathrm{~m}$ horizontal spacing and row spacing of $1.0 \mathrm{~m}$, internal steel pipe diameter $146 \mathrm{~mm}$ and wall thickness of $4.5 \mathrm{~mm}$. The high pressure jet grouting pile constructed between two rows of steel pipe pile and had a role as water-proof curtain. The depth of water-proof curtain was $4 \mathrm{~m}$ deeper than pumping well. Anchor and soil nailing is to control the deformation of the foundation pit construction, guarantee the stability of foundation pit. 


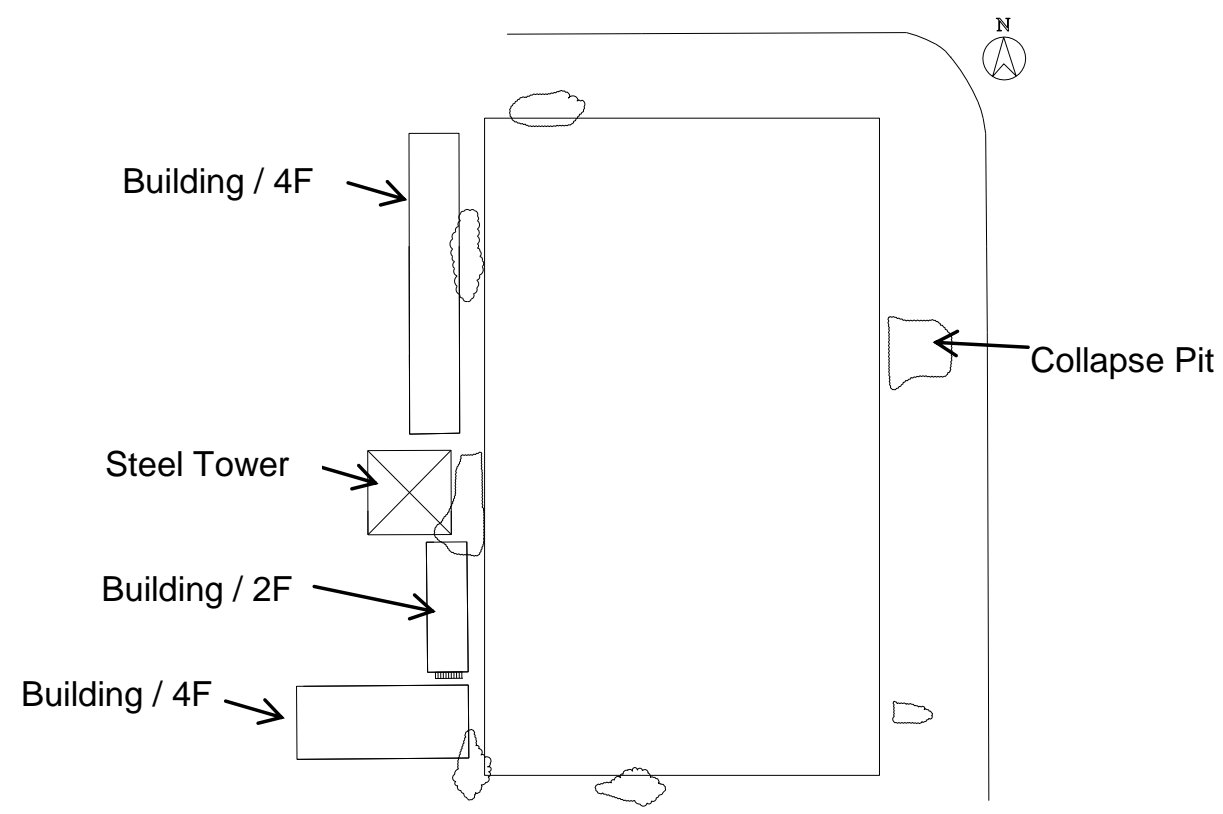

Figure 1. Plan of foundation pit

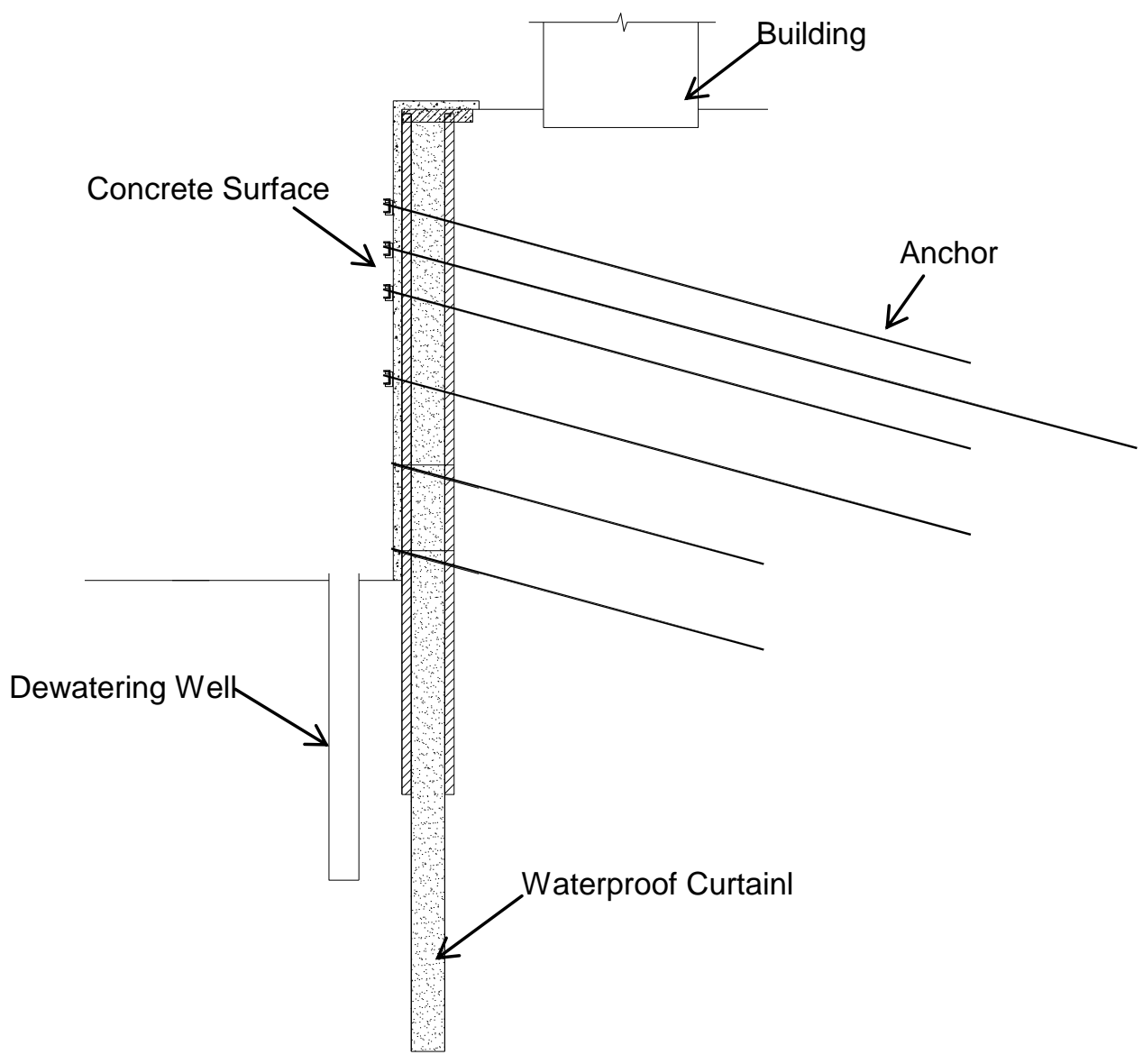

Figure 2. Support section of the west side of foundation pit

The heavy rainfall caused many foundation pit collapse and induced tilt and wall cracking of building around the pit. Surrounding buildings subsidence distribution as shown in Fig. 1. Partial collapse located below the building foundation, which induced foundation impending and indoor ground subsidence and some facilities damaged.

The height of water in foundation pit continues to rise after heavy rainfall and water depth is about $8.0 \mathrm{~m}$ after 10 days. After 20 days, the water level is changeless and similarly to the initial height provided by geotechnical investigation report, in which the average buried depth of water is $2.38 \mathrm{~m}$. 


\section{Engineering Geological Conditions}

According to the field of geotechnical engineering investigation report, the formation of soil layer is silt and cohesive soil interbedding and given priority to silt, briefly as follows:

(1) Miscellaneous fill: noise, the main ingredients for construction waste bricks, containing a little silty clay, the average thickness of $1.33 \mathrm{~m}$.

(2) Clay: palm red, plastic, no response of vibration, high toughness and strength, the average thickness of $1.52 \mathrm{~m}$.

(3) Silt: brown yellow, compact, vibration response of medium, low toughness and dry strength, the average thickness of $3.87 \mathrm{~m}$.

(4) Silty clay: tan, plastic, no response of vibration, toughness and dry strength of medium, the average thickness of $3.26 \mathrm{~m}$.

(5) Silt: brown yellow, close-grained, wet, the vibration response of medium, low toughness and strength, the average thickness of $4.93 \mathrm{~m}$.

(6) Fine sand: Yellowish gray, compact, saturated, the main ingredients of feldspar, quartz, grading, generally contain a little clay. Widely distributed in job site, are not penetrate this layer, the biggest thickness of $17.70 \mathrm{~m}$.

Area of groundwater for quaternary pore water. The stable layer of underground water level buried in the earth's surface under $1.65 \sim 3.25 \mathrm{~m}$, an average of $2.38 \mathrm{~m}$, the field pumping test to determine the composite average permeability coefficient $\mathrm{K}$ was $1.156 \mathrm{e} 10-4 \mathrm{~cm} / \mathrm{s}$, belong to medium permeable layer.

\section{Emergency Rescue Plan}

Because there is a numbers of collapses, leading to the west side building foundation hollowed, at the same time, the whole foundation pit is full of water, slope and the surrounding environment is in an imminent danger condition. Aimed at the situation of emergency rescue, main measures are as follows:

(1) Relevant personnel of the surrounding buildings emergency evacuation.

(2) Construction workers quickly organized and coordinated delivery of gravel by 350 workers on the collapse of parts of the backfill, especially located underneath the building collapse area, as shown in Fig. 5. Building collapse accident even severe cracking is avoid by sand and gravel backfill [5].

(3) Temporary grouting reinforcement for sand and gravel backfilling area is carry out by insert grouting pipe.

(4) Close inspection of pit slope and surrounding buildings [6].

Through the emergency response measures, buildings are not have a serious accident, foundation pit slope maintain stability, all above shown that the foundation pit supporting structure was not damaged. Emergency measures had gain a effective result and guarantee the stability of buildings foundation, which can avoid slope sliding again and provide favorable conditions for engineering strengthening lately.

\section{Accident Analysis}

Intrusion caused by the urban storm water, causing serious flooding pit, is have some force majeure. The west side of foundation pit is detected by underwater camera and shows that foundation pit side wall concrete surface crack and fall off, sliding soil happened and accumulated at slope toe, the thickness of sliding soil is about $2.0 \sim 2.5 \mathrm{~m}$.

Based on the detection of underwater camera, the reason of foundation impending and ground crack can be explained that a large number of soil mass outside had been carried into inner of foundation pit under high water head pressure and leads to the upper soil subsidence [7]. But steel pipe pile and anchor are not severely damaged, which indicates that the foundation pit construction quality is better and had necessities and feasibility to reinforce the pit. 


\section{Foundation Pit Reinforcement Scheme}

Grouting Reinforcement. The porosity of the soil can be filled compacted by grouting reinforcement, which was eroded by the heavy rain. With the grouting reinforcement, the soil shear strength can be improved, the bearing capacity of the anchor rod increased, so as to improve the safety factor of the foundation pit [8]. Simultaneously the waterproof curtain of the west and the south can be strengthen to reduce the influence of the settlement of the surrounding buildings.

Water accumulation in the foundation pit is equal to the back pressure stack, beneficial to the stability of the slope itself. If pumping before reinforcement, which is likely apply horizontal load to the existing foundation pit side wall and is adverse to safety of foundation pit. So it is to maintain a pit water level constant during grouting reinforcement, until to the new anchor constructed, the water level can be gradually reduced.

Soil around the foundation pit must be grouting reinforcement, while there are different grouting reinforcement scope restricted by the construction space. As shown in Fig. 4 is north of foundation pit profile after grouting reinforcement. Depth of grouting holes is $12 \mathrm{~m}$, diameter of the hole is $110 \mathrm{~mm}$, the steel pipe with diameter $25 \mathrm{~mm}$ be put into the hole when the hole is done. The steel pipe is processed into perforated tube shape, which has 2 openings around the circle according to $300 \mathrm{~mm}$ spacing [9]. Then the hole has been sealed using cement mortar and length of sealing is $2 \mathrm{~m}$. Pure cement paste has been grouting by the steel pipe under high pressure after sealing 24 hours. Cement slurry water cement ratio is $0.45 \sim 0.5$, the grouting pressure is $2.0 \sim 3.0 \mathrm{MPa}$.

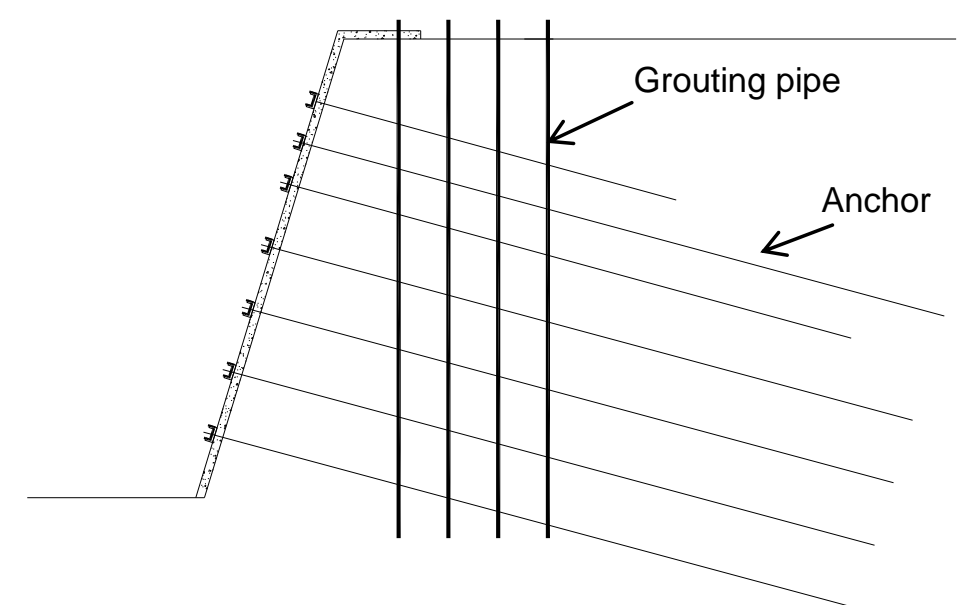

Figure 4. Grouting reinforcement of foundation pit

Foundation Pit Slope Reinforcement. Damage of shotcrete layer and compaction contact with the soil had been detected firstly before slope reinforcement construction [10]. According to detection, for the part of the surface damaged should eliminate damaged parts and applied again, for the poor contact with the soil on the surface part, should eliminate the original surface and to do oil grouting, concrete filling and other measures based on pore situation, and then sprayed concrete surface again.

Considering deformation of foundation pit side wall is larger and the bearing capacity of anchor has decreased, new prestressed anchor are needed for limited to lateral deformation of foundation pit wall and ensure the overall stability of foundation pit. Before the number of new anchor determination, the original bolt bearing capacity need to tested firstly. 36 anchor had been detected and there are 32 anchor is qualified under maximum test load, which displacement is relatively stable and meet the design requirements. The detection result shows that the quality of is good, no significantly affection generated to the bearing capacity of anchor by heavy rain. 
According to the surrounding environment and construction site condition, $2 \sim 3$ rows of prestressed anchor had been added on the slope around the foundation pit. The anchor is self-drilling hollow anchor poles with length 12 15m.

\section{Summary}

Through a foundation pit accident, this paper analyzed the causes of the accident, and formulated the emergency measures for rush repair and reinforcement scheme, late by field testing and monitoring data, to guide the later reinforcement construction, ensure the smooth implementation of the project, to provide technical reference for the similar accident.

\section{References}

[1] SU Peiren, Analysis on foundation pit accident causes in Taiyuan city, Shanxi Architecture, 41(2015):47-49.

[2] LI Pin, Analysis and Prevention of Deep Foundation Pit Accident, Urbanism and Architecture, 17 (2014):152-152.

[3] JIANG Ying, LI Mingming, Influence of Surrounding Geotechnical Environment upon Foundation Pit Excavation Support Viewed from a Foundation Pit Accident, Building Construction, 35(2013):368-369.

[4] XIONG Chuyan, TAO Rong, Cause-Analysis and Lessons Experienced from a Failure Accident of Foundation Pit Anchor Rod, Building Construction, 34(2012):535-537.

[5] LIU Guobin, WANG Weidong. Excavation Engineering Manual (second edition) [M]. Beijing: China Industry Press, 2009.

[6] YANG xuelin, the accident analysis and treatment of a foundation pit in Xiamen gulangyu, Fujian Architecture \& Construction, 2(2008):32-33.

[7] DENG Yong shan, HU Yi jun, ZHOU Jia mo, Analysis and Treatment of Foundation Accident of Downtown in Wuhan, Soil Engineering and Foundation, 22(2008):47-49

[8] YAN Bin, Analysis on the reason and reinforcing measures of some deep foundation pit accident, Shanxi Architecture, 34(2008): 86-87.

[9] Professional Standards Compilation Group of People's Republic of China. Technical specification for retaining and protection of building foundation excavations (JGJ120-2012) [S]. Beijing: China Architecture and Building Press, 2012.

[10] DU Chang chun, Accident Analysis and Technology Dispose of the Composite Soil-nailing Wall Support in the Soft-clay Deep Foundation Pit, Soil Engineering and Foundation, 21(2007):7-9 